\title{
Features of ideas about professionally important qualities in food industry workers with differences in the severity of properties of the nervous system
}

\author{
Anna Korochentseva ${ }^{1}$, Denis Dautov ${ }^{1}$, and Nelli Khachaturyan ${ }^{1, *}$ \\ ${ }^{1}$ Don State Technical University, 1, Gagarin Square, 344000, Rostov-on-Don, Russia
}

\begin{abstract}
Significant part of professionally important qualities for workers of the food industry is the balance of nervous processes. In this study, we decided to study the parameters, the certain severity of which, during the initial diagnosis of the future baker, can provide important information on how much he is predisposed to this type of activity. The purpose of the study is to study the features of ideas about professionally important qualities among workers of the food industry with differences in the severity of the properties of the nervous system. The main research method is the diagnostic technique for temperament of J. Strelau, Liszt Lipman (option II) and "Identification and analysis of professionally important qualities of specialists in the "man-technology"system. In total, 51 food industry workers took part in the study, 34 of which were women and 17 were men aged 23 to 45 years old. In the course of the study, we found differences in the severity of inhibition processes and the mobility of nervous processes among the employees of the baking shop. Next, we examined how these differences in the features of the nervous system can affect other professionally important qualities of bakery workers.
\end{abstract}

\section{Introduction}

The health of food consumers is an important issue that requires a responsible approach to training and staffing. The quality and safety of food products depend on food industry workers. Poor quality foods are causing many consumer health problems. These are food poisoning of various severity, diseases that occur when eating food containing dangerous microorganisms, or substances dangerous to humans $[1,2,3]$.

The constant changes characteristic of modern professions lead to the need for changes in the professional education of specialists. The priority areas for the development of modern professional education were aimed at the ideas of fundamental reconstruction and modernization of traditional educational algorithms in accordance with innovative spheres $[4,5]$. At the same time, constant, accelerating changes in society require more attention to the competencies of professional activities [6,7]. The professional qualities of food industry workers are no exception, they have a significant impact on the quality indicators

* Corresponding author: Nellja-nik@mail.ru 
of food products. In addition, the very choice of activity that does not correspond to the qualities available to a person can lead to the development of various psychosomatic and mental diseases $[8,9]$.

To achieve a high professional level in the field of professional activity, a specialist needs to possess certain professional knowledge and skills, competences, personal qualities that will contribute to the successful implementation of professional activities [10]. At the same time, high competition in all professional fields encourages the professional to constantly improve himself and update his professional skills [11,12].

In this regard, the problem of studying various aspects of professionally important qualities in various types of professional activity in modern psychology is becoming especially significant. Consideration of the problem of professionally important qualities involved G.A. Ball, V.A. Bodrov, T.M. Buyakas, A.A. Derkach, E.A. Klimov, Yu.V. Kotelova, V.L. Marischuk, K.K. Platonov, N.S. Pryazhnikov, A.D. Safin, E.S. Shelepova $[13,14,15]$. At the same time, ideas about the professionally important qualities inherent in the professional himself have not been studied enough. At the same time, it is obvious that a person who has an idea of those qualities that are important for the performance of his professional activity will develop them. It is these qualities that will be perceived by him as important in his profession. Professional representations themselves are a prerequisite for the formation of an active life position of a person, his success in professional activities [16]. Professional representations, at the initial stages of professional self-determination, become decisive for the further advancement of a person in the profession. The spontaneous development of professional ideas, misconceptions about competencies that are important for the profession, hinder professional growth, deform professional development [17].

Thus, ideas about the profession and professionally important qualities are of particular importance in human activity.

There are many works devoted to the study of both representations themselves (G. M. Andreeva, B. G. Ananyev, A. I. Dontsov, etc.) and a number of related aspects [18].

Some prerequisites that allow us to approach the definition of the significance of professional ideas are available in the works of V. D. Bragin, V. N. Obnosov and others $[19,20]$. Their role as regulators of professional self-determination was considered by V. G. Aseev, N. N. Gavrilenko, N. V. Komusova, T. V. Kudryavtseva, R. P. Milrud, and L. A. Sergeeva. These authors note that professional representations of a person have a significant impact on their professional development [21,22].

The peculiarity of the concepts of professional activity and related phenomena is that they unite a collective and individual in a person [23].

According to A.A. Bodalev's perception and understanding of each other by people depends on their professional affiliation, on the perception of themselves and others as professionals, as owners of certain knowledge and abilities [24].

E.A. Klimov notes that ideas about professional activity are important components of the image of the world, its similarities and differences among different people [21].

It should also be taken into account that the person's own ideas about professionally important qualities are determined by both environmental (acquired in the learning process) factors and hereditary factors [25]. Each person is the owner of certain qualities. Therefore, we can say that the natural inclinations of a person make him more or less prepared for the successful mastery of a particular profession. A reflection of the combination of hereditary and acquired is the concept of "quality". Quality can be called the current level of manifestation of any side of a person's capabilities, regardless of whether this level is due to hereditary characteristics, or environmental influences [26]. The hereditary factors that are determined by genetics include constitutional and psychophysiological characteristics, such as properties of the nervous system, mental processes associated with perception, 
attention. It is the properties of the nervous system that make it possible to reveal the correlation of typical and individual properties of a person in profession [27].

The specifics of a particular activity has numerous intricacies that have to work to face the man. It is not surprising that properties of the nervous system play an important role in determining the success, effectiveness, quality and speed of performance.

Features of the emotional sphere, speed of reaction, stress tolerance, willingness to take risks, the power of processes of excitation and inhibition, mobility of nervous processes. The alloy of these qualities not only ensures the success of professional activities, but also a sense of belonging to a particular profession. The more multifaceted this activity, the greater the range of qualities necessary for the person [28].

The "human-technology" field is one of the most complex systems. A variety of activities were rated to this area requires complex operations from a person and involves difficult working conditions.

Work with any technique is accompanied by a varying degree of risk, therefore, a specialist must have a highly developed sense of preparedness for risk, he must be able to assess the justification of this risk without losing self-preservation, have a high degree of self-control, demonstrate the speed of decision-making, and adhere to the rules and technical instructions, prescriptions, rules of operation of equipment $[29,30]$.

A set of certain individual psychological qualities of the employees of the bakery shop largely depends on its narrow specialization. But common features can be highlighted. A master baker is a person with responsibility, technical competence, interest in the technological process of preparing products. He should develop attentiveness, memorization, sensory and motor qualities [16].

The main feature of the baker's work, regardless of the place of work, is that he works near the oven, in a room with high air temperature. In order to avoid burns, the baker must strictly adhere to the technique for performing various actions. At the same time, the baker should carefully monitor the products, detecting the necessary intervals, he should have sufficient switching attention and a certain set of motor skills. Thus, it can be stated that the baker, in addition to physical endurance, attentiveness, delicate sense of smell and taste sensitivity, must have qualities that ensure clear coordination of hand movements, concentration, observation, balance of the nervous system, etc.

In this study, we decided to study the parameters, the certain severity of which, during the initial diagnosis of the future baker, can provide important information on how much he is predisposed to this type of activity, how much his ideas about professionally important qualities correspond to the requirements of the profession. Taking into account the properties of the nervous system as the most objective indicators will allow for a better selection of personnel and will reduce staff turnover.

\section{Materials and methods}

Based on theoretical assumptions, we formulated the goal of the study - to research the features of ideas about professionally important qualities in food industry workers with differences in the severity of the properties of the nervous system. The hypothesis of the study was the assumption that differences in ideas about professionally important qualities in food industry workers with differences in the severity of the properties of the nervous system can be detected.

To research the severity of the processes of excitation, inhibition and mobility of nervous processes, we used the method of diagnosing the temperament of $\mathrm{Zh}$. Strelau. The following methods were used to research the ideas of bakery workers about professionally important qualities necessary for their activities and their severity: the Lipman list method (Option II), as well as the method "identification and analysis of professionally important 
qualities of specialists in the" man-technique" system, thanks to which we were able to determine the severity of professionally important qualities in each group of subjects. A total of 51 food industry workers took part in the study, including 34 women and 17 men aged 23 to 45 years. The reliability of the obtained data was provided by calculating the significance of differences according to the student's T-test. Data processing was performed using the computer program "IBM SPSS Statistics for Windows".

\section{Result}

At this stage of the research, we conducted a comparative analysis of the predominance of the processes of excitation, the strength of the processes of inhibition, and revealed the degree of mobility of the nervous processes in the employees of the baking shop.

39 baker's, the power of the process of inhibition over excitation prevails. The 12 baker's are dominated by the strength of the excitation process, as well as the strength of the processes of inhibition. Let us consider in more detail what means the predominance of one process over another, and what role the mobility of nervous processes plays.

High scores indicate a strong response to arousal, stimulus. Such a person does not show signs of outrageous inhibition. It is characterized by quick inclusion in work, productivity and achievement of high productivity; low fatigue, and as a result, high performance and endurance.

High scores on the scale "level of inhibition processes" characteristic of 39 employees of the bakery shop mean that stimuli of excitation are easily quenched, there is a quick response to responses to simple sensory signals, a good reaction. Such people have high self-control, alertness, composure in behavioral reactions.

The level of mobility of nervous processes in subjects with high points means easy implementation of the switching neural processes from excitation to inhibition and Vice versa. A quick transition from one type activity to another, fast switching, determination, courage in behavioral reactions.

Further, according to the results of the research the manifestations of the processes of excitation, inhibition and mobility of nervous processes in food industry workers, all of them divided into 2 groups for further analysis.

In 39 workers of a bakery section the strength of the processes of inhibition dominates over excitation. But steadiness of nerve processes in the normal range. In terms of mobility of nervous processes, the data of the subjects the results are normal limits (hereafter group 1). In 12 subjects the prevailing unbalance in the direction of excitation, the indicators of balance in the normal range (hereafter group 2).

In the second stage of the study we analyzed the results obtained by the method of "Identification and analysis of professionally important qualities of specialists of the system "man-machinery" by which we were able to determine the severity of professionally important qualities in each group.

On the basis of the obtained data shows that the most significant differences are observed in the areas of "interest in science", "physical development", "having sense of responsibility", "health", "attention", "the resistance to external stimuli" and "technical literacy".

Representatives of group 2 have significantly lower rates compared to group 1, and according to the results of the methodology, these employees are not recommended for work in the "man-technique" system. 


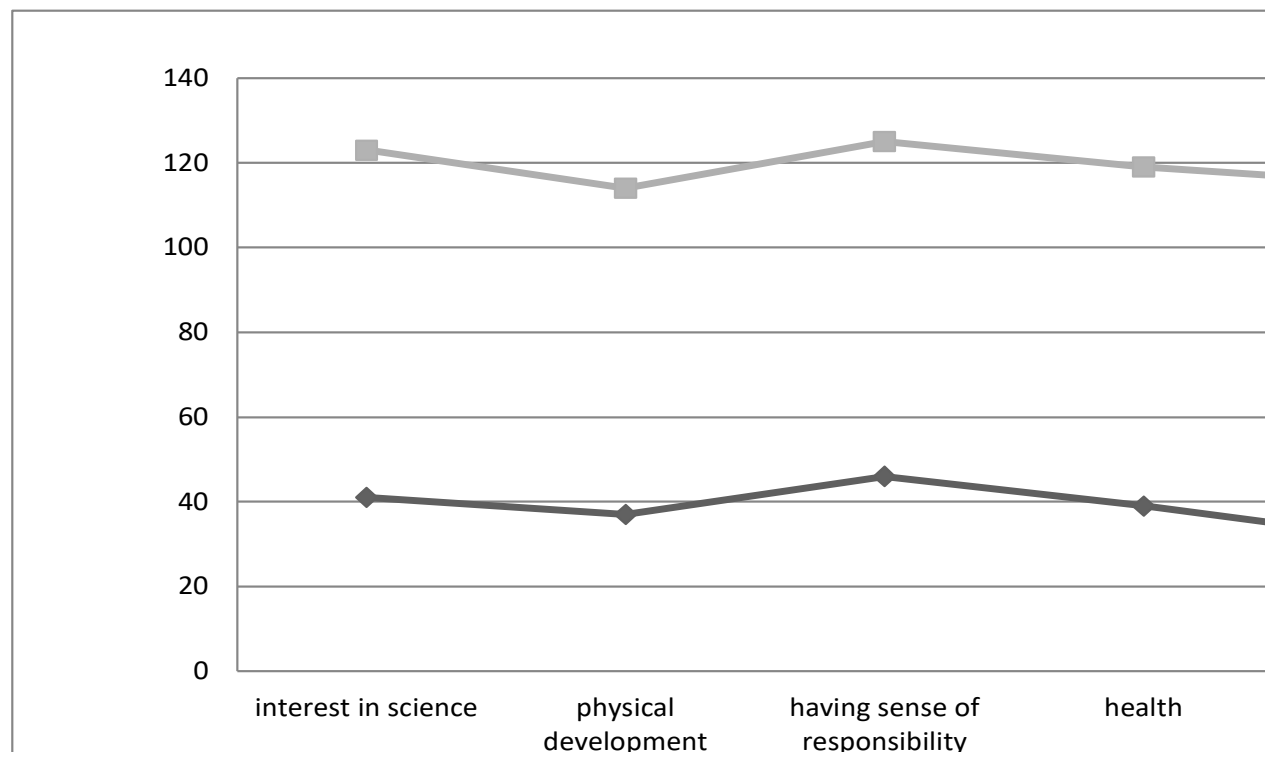

Fig. 1. The indicators of the spheres in which the greatest differences are found between employees of the bakery workers.

Further, to determine the significance of the differences between the employees of the bakery shop from group 1 and group 2, in the severity of such indicators as: interest in technology; physical development; a sense of responsibility; speed of decision making (reaction); health conditions; Attention; psychological stability; a sense of selfpreservation; resistance to external irritants; tendency to monotonous work; technical literacy, we applied Student's T-test. As a result, the following data were obtained.

Significant differences were found in the severity of indicators on the scales: "Interest in technology" $(\mathrm{t}=3.317)$; "Physical development" $(\mathrm{t}=3,322)$; "Attention" $(\mathrm{t}=5.531)$; "Resistance to external stimuli" $(\mathrm{t}=4.042)$; "The tendency to monotonous work" $(\mathrm{t}=$ $2,857)$; "Technical literacy" $(\mathrm{t}=3,334)$. For employees of the baker's from group 1 , this indicator is significantly higher.

Table 1. Significance indicators of differences in the studied indicators between the employees of the baker's according to the Student's T-test.

\begin{tabular}{|l|c|c|c|c|c|c|}
\hline & F & Sig. & $\mathbf{t}$ & $\begin{array}{c}\text { Sig. (2- } \\
\text { tailed) }\end{array}$ & $\begin{array}{c}\text { Mean } \\
\text { Difference }\end{array}$ & $\begin{array}{c}\text { Std. Error } \\
\text { Difference }\end{array}$ \\
\hline $\begin{array}{l}\text { Interest } \\
\text { technique }\end{array}$ & 9.589 & 0.004 & 3.317 & 0.002 & -1.06 & 0.319 \\
\hline $\begin{array}{l}\text { Physical } \\
\text { development }\end{array}$ & 24.900 & 0.000 & 3.222 & 0.003 & -1.18 & 0.366 \\
\hline $\begin{array}{l}\text { Sense } \\
\text { responsibility }\end{array}$ & 10.321 & 0.003 & 2.126 & 0.042 & -0.59 & 0.276 \\
\hline Reaction & 0.560 & 0.460 & 1.664 & 0.107 & -0.57 & 0.345 \\
\hline Health status & 11.425 & 0.004 & 2.416 & 0.025 & -0.96 & 0.398 \\
\hline Attention & 15.299 & 0.001 & 5.531 & 0.000 & -1.84 & 0.332 \\
\hline Mental stability & 1.995 & 0.168 & .735 & 0.468 & -0.29 & 0.400 \\
\hline $\begin{array}{l}\text { Self } \\
\text { preservation }\end{array}$ & 3.035 & 0.092 & 1.041 & 0.307 & -0.41 & 0.392 \\
\hline $\begin{array}{l}\text { Resistance to } \\
\text { external irritants }\end{array}$ & 0.473 & 0.497 & 4.042 & 0.000 & -1.50 & 0.372 \\
\hline
\end{tabular}




\begin{tabular}{|l|c|c|c|c|c|c|}
\hline $\begin{array}{l}\text { The tendency to } \\
\text { monotonous } \\
\text { work }\end{array}$ & 0.952 & 0.337 & 2.857 & 0.008 & -1.26 & 0.442 \\
\hline $\begin{array}{l}\text { Technical } \\
\text { literacy }\end{array}$ & 0.328 & 0.571 & 3.334 & 0.002 & -1.86 & 0.556 \\
\hline
\end{tabular}

Next, we examined the perceptions of employees about professionally important qualities using the Lipman List method (option II), which allows us to research the perceptions of subjects of labor (employees of the bakery shop) about the individual psychological characteristics necessary for the chosen activity and evaluate their degree of significance.

We have established that, in the opinion of employees of the bakery shop from group 1, the most important properties necessary for them to successfully carry out this professional activity are: observation, motor, sensory, imaginative and volitional properties. This is shown in Figure 2.

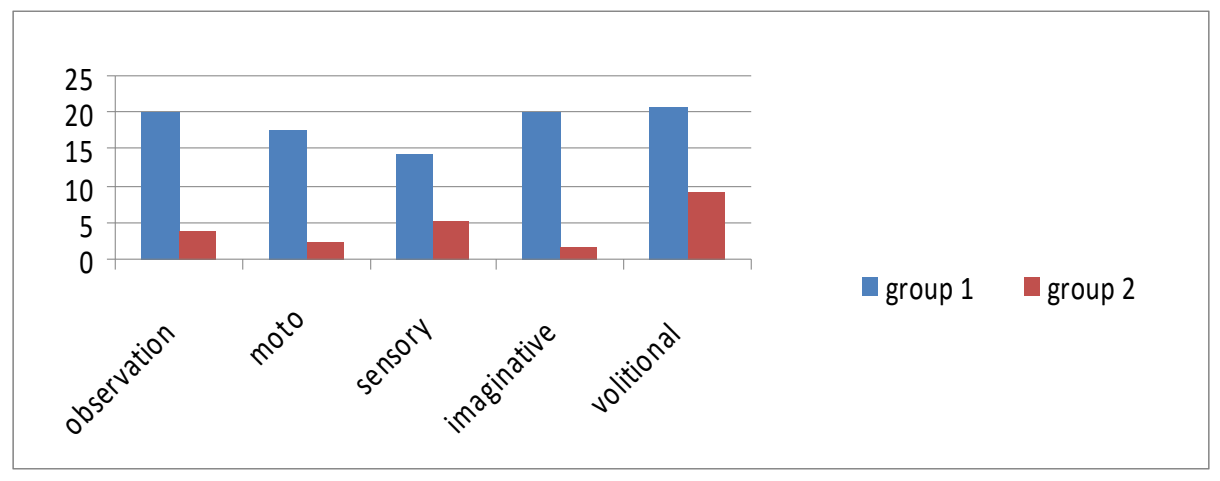

Fig. 2. Indicators of severity, professionally important qualities, which, in the opinion of the employees of the baking shop, are important for the successful implementation of their professional activities.

Further, to determine the significance of the differences between the employees of the bakery shop from group 1 and 2 in the ideas about the need for expressiveness in professional activity of such personality traits as: attentive; observation; mnemonic; motor; sensory; imaginative; mental emotional; strong-willed; speech; we applied Student's T-test. As a result, the following results were obtained:

Table 2. Significance indicators of differences in the studied indicators between the employees of the baker's according to the Student's T-test.

\begin{tabular}{|l|c|c|c|c|c|c|}
\hline & & Sig. & $\mathbf{t}$ & $\begin{array}{c}\text { Sig. (2- } \\
\text { tailed) }\end{array}$ & $\begin{array}{c}\text { Mean } \\
\text { Difference }\end{array}$ & $\begin{array}{c}\text { Std. Error } \\
\text { Difference }\end{array}$ \\
\hline attentive & 0.295 & 0.591 & 0.203 & 0.841 & -0.0285 & 0.14055 \\
\hline observation & 1.211 & 0.280 & 4.733 & 0.000 & -0.7140 & 0.15086 \\
\hline mnemonic & 0.028 & 0.869 & 0.007 & 0.995 & -0.0009 & 0.12850 \\
\hline motor & 0.898 & 0.351 & 5.711 & 0.000 & -0.5917 & 0.10360 \\
\hline sensory & 0.955 & 0.337 & 3.550 & 0.001 & -0.3110 & 0.08759 \\
\hline imaginative & 12.893 & 0.001 & 6.457 & 0.000 & -0.9057 & 0.14027 \\
\hline mental & 0.082 & 0.777 & -3.352 & 0.002 & 0.5658 & 0.16877 \\
\hline emotional & 6.668 & 0.015 & -6.443 & 0.000 & 0.8342 & 0.12947 \\
\hline willpower & 0.564 & 0.459 & 1.958 & 0.060 & -.3175 & 0.16221 \\
\hline speech & 0.046 & 0.832 & -4.209 & 0.000 & 0.5991 & 0.14235 \\
\hline communicative & 0.739 & 0.397 & -2.233 & 0.033 & 0.3132 & 0.14023 \\
\hline
\end{tabular}


Significant differences were found in the severity of indicators on the scales of "Observation" ( $\mathrm{t}=4.733)$; "Motor properties" $(\mathrm{t}=5.711)$; "Sensory properties" $(\mathrm{t}=$ $3,550)$; "Imaginative properties" $(\mathrm{t}=6.457)$; in employees of the baker's from group 1 , compared with the subjects from group 2, these indicators are significantly higher. On the scales: "Thinking properties" $(\mathrm{t}=-3.352)$; "Emotional properties" $(\mathrm{t}=-6.443)$; "Speech properties" $(\mathrm{t}=-4.209)$; in the employees of the bakery shop from group 1 , these indicators are expressed significantly lower than in the subjects of group 2 .

\section{Discussion}

Thus, as a result of a study of the perceptions of food industry workers about individual psychological characteristics necessary for the successful implementation of their professional activities, the following data were obtained.

Significant differences were found in the perceptions of the employees of the baker's from group 1 and 2 about the properties professionally important for their type of activity.

The highest statistical differences were found in the severity of indicators on the scale of "Observation", "Motor" and "Imaginative" properties, for employees of the bakery shop from group 1, the indicators on these scales are significantly higher than for the subjects of group 2. These results are fully consistent with the specifics activities of food industry workers. Observability in their activities plays an important role. Motor activity is just as important for the baker's activities, because the specifics of their activities require precise and quick movements necessary not only to increase labor productivity, but also to ensure safety and to exclude burns and injuries in the process of production. An important role in the activities of the baker is also played by the imaginative properties associated with the processes of mental construction of images of such objects and phenomena that are not directly perceived, but pass on, based on existing ideas about related objects and phenomena. These processes are directly related to the possibility of representing the final product of their activities.

\section{Conclusion}

In the course of the study, we found differences in the severity of inhibition processes and the mobility of nervous processes in employees of the baker's. For most bakery workers, the results are within normal limits, while for some, imbalance toward excitement prevails. High mobility of nervous processes provides the most effective quick switching of attention of the baker's from one type of activity to another. And balance indicators within normal limits confirm high resistance to monotonous work and external stimuli, the ability to control one's emotional state, and the ability to remain calm even in stressful situations.

Next, we examined how these differences in the features of the nervous system can affect other professionally important qualities of bakery workers.

The largest statistical differences when comparing employees of the baker's with the balance of the nervous system processes and the power of the process of inhibition over excitation prevails (group 1) compared with workers in which the imbalance in the direction of excitation predominates were found on the scales "Attention" and "Resistance to external irritants". Significant differences were also found in the severity of indicators on the scales: "Interest in technology"; "Physical development"; "The presence of a sense of responsibility"; "Health conditions"; "The tendency to monotonous work"; "Technical literacy". At employees of the baker's from the first group, these indicators are significantly higher. 
A tendency towards greater severity of indicators on the scale of "Decision-making speed (reaction)" was found among the employees of the baking shop from the first group.

Statistical differences were also found in the severity of indicators on the scale of "Observation", "Motor" and "Imaginative" properties, for employees of the bakery shop of group 1, indicators on these scales are significantly higher than for subjects of group 2 . Observation plays an important role for their activities. Motor activity is just as important for the baker's activities, because the specifics of their activities require precise and quick movements necessary not only to increase labor productivity, but also to ensure safety and to exclude burns and injuries in the process of production. An important role in the activities of the baker is also played by the imaginative properties associated with the processes of mental construction of images of such objects and phenomena that are not directly perceived, but pass on, based on existing ideas about related objects and phenomena. These processes are directly related to the possibility of representing the final product of their activities.

Such results are fully consistent with the specifics of the activities of food industry workers, but based on the data obtained, it is necessary to take into account the fact that the balance of nervous processes is an important part of professionally important qualities for food industry workers. This will ensure the proper quality of their work, switchability and stability of attention, the possibility of long-term focus on activities that require attention and emotional stability.

\section{References}

1. K. Fan, M. Zhang, Critical Reviews in Food Science and Nutrition 59(14), $2202-$ 2213 (2019) doi: 10.1080/10408398.2018.1441124

2. R. Nayak, P. Waterson, Food Control 73(B), 1114-1123 doi: https://doi.org/10.1016/j.foodcont.2016.10.061

3. L. Vartanian et al., Health Psychology 36(4), 365-369 (2017) doi: 10.1037/hea0000447

4. A. Cook-Sather, Higher Education Research \& Development 37(5), 923-936 (2018) doi: https://doi.org/10.1080/07294360.2018.1457629

5. J. de Bilde, M. Vansteenkiste, W. Lens, Learning and Instruction 21(3), 332-344 (2011) doi: 10.1016/j.learninstruc.2010.03.002

6. Y. Kuzminov, D. Peskov, Issues of Education 3, 202-233 (2017) doi: 10.17323/18149545-2017-3-202-233

7. C. Beard, B. Humberstone, B. Clayton, Teaching in Higher Education 19(6), 630643 (2014) doi: https://doi.org/10.1080/13562517.2014.901950

8. E. Shubnikova, II International Scientific-Practical Conference Psychology of Extreme Professions (2019) doi: https://doi.org/10.2991/ispcpep-19.2019.45

9. D. Zinovyeva et al., II International Scientific-Practical Conference" Psychology of Extreme Professions, Atlantis Press (2019) doi: https://doi.org/10.2991/ispcpep19.2019.57

10. S. Gilmanshina, R. Sagitova, N. Fedotova, 3rd International Conference on Social, Economic, and Academic Leadership (2019) doi: https://doi.org/10.2991/icseal19.2019.39

11. O. Chesnokova, S. Churbanova, S. Molchanov, Cultural-Historical Psychology 15.4, 109-118 (2019) doi: 10.17759/chp.2019150411 
12. A.-M. Nisula, S. Metso, Journal of Education and Work 32(6-7), 552-569 (2019) doi: $10.1080 / 13639080.2019 .1673884$

13. E. Zeer et al., Eurasian Journal of Analytical Chemistry 13(1b), 1-9 (2018) doi: $10.29333 /$ ejac/102241

14. O. Popova, The world of education - education in the world 2, 193-202 (2014)

15. I. Hasanova, S. Kotova, E. Kandrashina, International Journal of Environmental \& Science Education 11(14), 6976-6987 (2016)

16. M. Naumenko, E. Rogova, E. Rogov, Studies in Humanities and Social Sciences 135 , 135-142 (2019)

17. E. Rogov, L. Zheldochenko, II International Scientific-Practical Conference "Psychology of Extreme Professions" (ISPCPEP 2019) 321, 175-179 (2019) doi: 10.2991/ispcpep-19.2019.42

18. M. Akimova et al., Intellectual ICPE International Conference on Psychology and Education 33, 1-7 (2017) doi: 10.15405/epsbs.2017.12.1

19. L. Zheldochenko, N. Epritskaya, SHS Web of Conferences 70, 1-6 (2019) doi.org/10.1051/shsconf/20197008047

20. V. Tolochek, V. Vilches-Nogerol, II International Scientific-Practical Conference Psychology of Extreme Professions, Education and Humanities Research (ISPCPEP 2019) 321, 204-207 (2019) doi.org/10.2991/ispcpep-19.2019.49

21. N. Karimova, Eastern European Scientific Journal 2 (2018)

22. J. Tushnova, J. Rashchupkina, N. Khachaturyan, SHS Web of Conferences EDP Sciences 70 (2019) https://doi.org/10.1051/shsconf/20197008041

23. N. Bakholskaya et al., Dilemas Contemporáneos: Educación, Política y Valore 6(3) (2019)

24. E. Sheremetyeva, E. Plotnikova, A. Kovaleva, Sustainable development under the conditions of European integration 1, 398-414 (2019)

25. C. Haworth et al., Molecular Psychiatry 15, 1112-1120 (2010)

26. V. Zakirova, E. Purik, International journal of environmental and science education 11(9), 2323-2332 (2016) doi: 10.12973/ijese.2016.608a

27. I. Petukhov et al., 2016 IEEE 8th International Conference on Intelligent Systems (IS), 672-679 (2016) doi: 10.1109/IS.2016.7737383

28. V. Kalnysh, R. Stasyshyn, M. Oliskevych, Internal Medicine and Medical Investigation Journal 4(2) (2019) doi: 10.24200/imminv.v4i2.212

29. S. Zhdanova, et al., International Journal of Psychophysiology 131, 178-179 (2018) doi: doi.org/10.1016/j.ijpsycho.2018.07.469

30. P. Converse et al., Journal of Research in Personality 73, 82-92 (2018) doi: 10.1016/j.jrp.2017.11.002 